\title{
Isoflurane Induces Neurodegenerative Changes in Retinal Pigment Epithelial Cells
}

\section{Amro Ali*, Wandel TL and Sharma S \\ Department of Ophthalmology, New York Medical College, USA}

*Corresponding author: Amro Ali, Department of Ophthalmology, New York Medical College, 40 Sunshine Cottage Road, Valhalla, NY 10595, USA, E-mail: amro.ali9@icloud.com

\section{Research Article}

Volume 3 Issue 2

Received Date: February 17, 2018

Published Date: March 05, 2018

\section{Abstract}

Background: Inhaled anesthetics have the potential to induce neurons to undergo cellular changes seen in Alzheimer's disease. Given the similarities between Alzheimer's disease and age-related macular degeneration (AMD), we propose that similar changes might be observed in retinal cells exposed to isoflurane.

Methods: Human derived retinal pigment epithelial cells (ARPE-19) were exposed to 1.2\% and 3.5\% isoflurane for four hours. Markers of apoptosis and cellular inflammation within the lysate of isoflurane exposed cells and control cells were measured using a luminometer. Transcript levels of genes involved in apoptosis, cell cycle entry and progression, and the formation of $\beta$-amyloid plaque were measured using real time PCR.

Results: Isoflurane exposed cells had increased levels of reactive oxygen species (ROS/RNS) and caspases 3 and 7 as determined by a luminometer. Isoflurane treated cells demonstrated significant increases in transcription of several genes linked to the formation of $\beta$-amyloid, including BACE1, APPBP1, APPBP2, APH1A, APH1B and NCSTN. Significant increases in transcription of cell cycle markers POLD1, MDM2, CCNA2 and RBL2 were observed, as was an increase in the transcription of JUN which is the first marker for apoptosis cascade.

Conclusions: ARPE-19 cells that were exposed to isoflurane in vitro displayed many changes that have been associated with the development of neurodegenerative disease. A potential link between isoflurane exposure and the development of AMD should be further explored.

Keywords: Neurodegenerative; Retinal Pigment; Epithelial Cells; Isoflurane; Proinflammatory

Abbreviations: AD: Alzheimer disease; AMD: Age Related Macular Degeneration; POCD: Post-Operative Cognitive Dysfunction; ROS: Reactive Oxygen Species; RNS: Reactive Nitrogen Species.

\section{Introduction}

Aging is one the most common processes associated with an increase in the likelihood of Alzheimer disease (AD) and Age Related Macular Degeneration (AMD), two conditions characterized by many shared features such as the formation of $\beta$-amyloid $(A \beta)$ and tau protein deposits in neurons [1-3]. An estimated 200 million patients worldwide undergo surgery each year, but only the elderly ( $\geq 65$ years old) population has a higher probability of undergoing general anesthesia, which has 


\section{Open Access Journal of Ophthalmology}

been found to been associated with post-operative cognitive dysfunction (POCD) $[4,5]$.

Neurodegenerative diseases affect more than $11.5 \%$ of the population in the United States and results in costs of around $\$ 343$ billion, yet their etiology is still unclear. Both Isoflurane and Sevoflurane have been shown to increase $\beta$-amyloid protein levels and induce apoptosis in studies using in vitro and animal models [6-9]. Inhaled anesthetics have also been shown to enhance $\beta$-amyloid oligomerization and cytotoxicity [10]. Other studies have shown a potential link between Isoflurane exposure and the generation of proinflammatory cytokines in neuronal tissue [11].

Accumulating evidence is compelling the anesthesia community to question the safety of general anesthesia at the extremes of age. Preclinical data suggest that inhaled anesthetics have profound and long-lasting effects on neurodevelopmental periods by increasing neuronal cell death (apoptosis) and reducing neurogenesis $[12,13]$. Previous studies have also explored the impact of inhaled anesthetics and have demonstrated that early exposure to Isoflurane and other inhaled anesthetics can affect social behavior, increase cognitive dysfunction, and lead to delays in reading, written language and math learning [14-16]. Several retrospective cohort studies have attempted to link AD diagnosis among the elderly with previous general anesthesia exposure but the results have been inconclusive [17-19]. Very few studied have investigated the effects of anesthetics on the retinal neurons where theynoticed ocular electro-physiological changes (20) in postoperative patients, albino rabbits, and in Drosophila melanogaste after exposure to volatile anesthetics [20-23].

Despite the pathological similarities between $\mathrm{AD}$ and AMD, a potential link between anesthetics and the pathogenesis of AMD has not been fully explored. Studying of neurodegenerative diseases are extremely difficult because these diseases often have a protracted course and their etiology is multifactorial and unclear. Using the retina in studying neurodegenerative disease will give the best model for gaining a better understanding of the protracted course of testing and the effect of different neuroprotective agents. The main advantage in studying the retina as model for neurodegenerative diseases is the ability of multiple in vivo imaging with higher resolution camera without the need of scarifying large number of animals and decreases the cost of study.

In order to determine the effects of anesthetics on the retina, we exposed Retinal Pigment epithelial cell line (ARPE19- ATCC; American Type Culture Collection), cells to isoflurane at concentrations of $1.2 \%$ and $3.5 \%$ for four hours. Cells were rested for two hours after the exposure before running any assay in the incubator. Our goal was to determine whether exposure to isoflurane could initiate retinal cells to undergo the changes that have been observed within retinal cells in the context of AMD. Some of these changes include increases in $\beta$-amyloid production, pro-apoptotic enzyme activity, Reactive Oxygen Species (ROS) and reactive nitrogen species (RNS) formation and a potential reemergence of cell cycle specific markers $[24,25]$.

\section{Methods}

\section{Cell preparation}

Experiments were conducted using human derived ARPE-19-ATCC. The cells were maintained in the conditions similar to that described by Schnichels S, et al. [26]. DMEM containing 4mM L-glutamine, $10 \%$ fetal bovine serum, $100 \mathrm{U} / \mathrm{ml}$ penicillin and $100 \mathrm{U} / \mathrm{ml}$ streptomycin at $37^{\circ} \mathrm{C}$ and $5 \% \mathrm{CO}_{2}$. The cells were seeded at a density of 80,000 cells/well in a 6-well plate.

\section{Exposure to Isoflurane}

Experimental cells were then placed in a BillupsRothenberg chamber and exposed to two different concentrations of Isoflurane for 4 hours: $1.2 \%$, and $3.5 \%$.We used the chamber according to the manufacturer's protocol. Briefly, the humidified chamber was keptat $37^{\circ} \mathrm{C}$ and $5 \% \mathrm{CO}_{2}$ environment. The chamber was connected to an Isoflurane machine where it was adjusted to the percentage of gas that was mixed with normal atmospheric oxygen levels of $21 \%$.

\section{Cell Resting}

The cells were placed in a clear 6-well cell culture plate for two hours to rest in the incubator. Then, all the following experiments and assays were performed to compare the cells that had been exposed to Isoflurane $(1.2 \%$, and $3.5 \%$.) to control cell line, without exposure to isoflurane.

\section{Caspase Glo 3/7 Activity Kit (Promega)}

We used the Caspase Glo 3/7 activity kit (Promega) according to the manufacturer's instructions on either cells that had been treated with anesthetic as previously described, or on lysates according to the protocol provided by the company. Finally, a luminometer was 


\section{Open Access Journal of Ophthalmology}

used to measure luminescence according to the protocol provided by the company after two hours of exposure.

\section{Reactive Oxygen Species (ROS) and Reactive Nitrogen Species (RNS) Measurement}

ROS/RNS levels were measured using the OxiSelect ${ }^{\mathrm{TM}}$ ROS/RNS assay kit (Cell Biolabs, Inc.). The experiments were performed according to the protocol provided by the company. Briefly, the cells were placed in a clear 6well cell culture plate for two hours in the incubator. Cells were lysed using RIPA buffer (Millipore Corp.) in 1x PBS and eventually read with a fluorometric plate reader at $480 / 530 \mathrm{~nm}$ according to the protocol provided by the company.

\section{RT-PCR}

Gene expression analysis was performed using BioRad custom prime real time PCR plates and CFX96 Touch Real-Time PCR Detection System. 96- PCR plates can be user-designed with Prime PCRTM SYBR $\AA$ Green assays. Custom primer assays can also be added. Primer pairs are lyophilized in the wells on the plate. Commonly used reference gene assays, GAPDH were used to normalize for variation in the amount of input messenger RNA (mRNA) among samples. All primers for the studied genes have been prepared and provided by BioRad.

RNA isolation and purification was conducted in the sample(s) using Aurum isolation kits. The Aurum total RNA mini kit (catalog \#732-6820) enable RNA isolation from a wide range of cells and include a DNase digestion step to ensure DNA-free total RNA. Use the iScript family of reverse transcription reagents for cDNA synthesis. The iScript advanced cDNA synthesis kit was used during wetlab validation of Prime PCR assays. Protocols for preparing real-time PCR reaction mix were described according to format (96-well plates) BioRad manual. PCR plate was loaded on the real-time PCR instrument and program the thermal cycling protocol according BioRad manual. Data was processed and analyzed using CFX Manager or other analysis software.

\section{Results}

\section{Caspase 3/7 Activity}

An increase in Caspase 3/7 levels among RPE cells that had been treated with Isoflurane for 4 hours (Figure 1) was observed. Control untreated cells demonstrated a base level of both caspase 3/7. Although caspase 3/7 levels increased in cells exposed to both concentrations of isoflurane, a significant increase was observed after exposure to a concentration of $3.5 \%$ isoflurane. The caspase levels seem to decrease over time in the control and both treatment conditions.

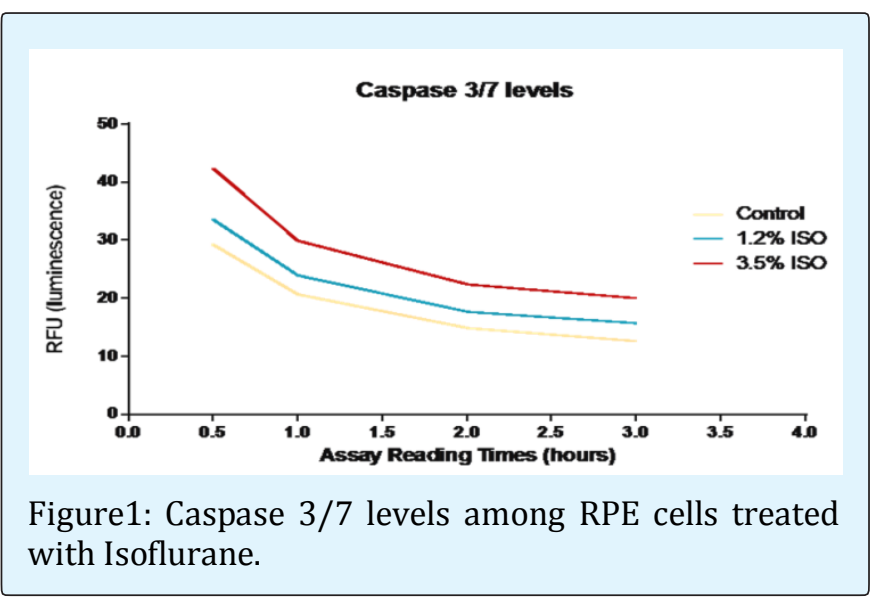

Caspase 3/7 levels among RPE cells that have been treated with $1.2 \%$ and $3.5 \%$ Isoflurane were compared to control untreated cells. The graph represents multiple readings of Caspase 3/7on the plate reader at $480 \mathrm{~nm}$ (excitation) and $530 \mathrm{~nm}$ (emission) taken at different time points after performing the assay. The data reveals a concentration dependent increase in caspase 3/7 among RPE cells that have been treated with Isoflurane.

\section{Reactive Oxygen Species (ROS) and Reactive Nitrogen Species (RNS)}

We observed an increase in ROS/RNS levels in RPE cells that have been treated with Isoflurane for 4 hours (Figure 2). Control untreated cells showed a base level of ROS/RNS. Although ROS/RNS levels increased in cells exposed to both concentrations of isoflurane, a more significant increase was observed after exposure to a concentration of $3.5 \%$ isoflurane. In control and treatment conditions, ROS/RNS levels appear to increase over time.

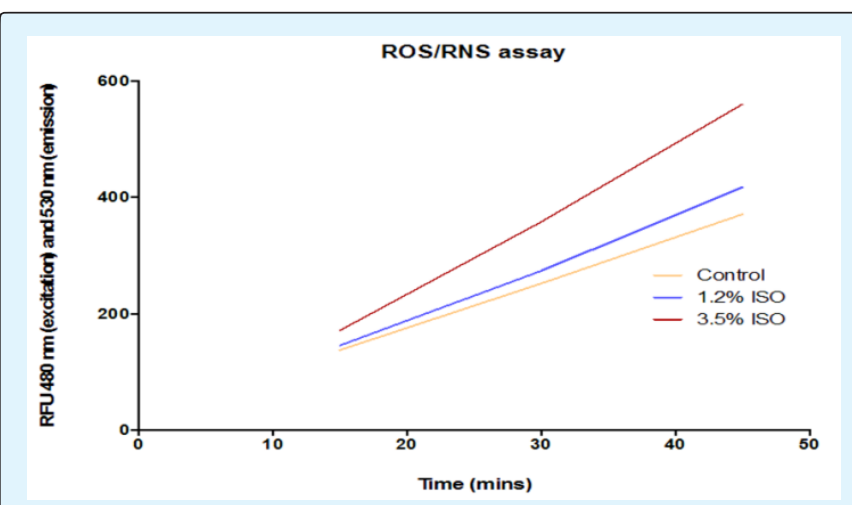

Figure 2: ROS/RNS levels among RPE cells treated with Isoflurane. 


\section{Open Access Journal of Ophthalmology}

ROS/RNS levels among RPE cells that have been treated with $1.2 \%$ and $3.5 \%$ Isoflurane were compared to control untreated cells. The graph represents several readings of ROS levels on the plate reader at $480 \mathrm{~nm}$ (excitation) and $530 \mathrm{~nm}$ (emission) taken at different time points after performing the assay. The data reveals a concentration dependent increase in ROS levels among RPE cells that have been treated with Isoflurane.

\section{$\beta$-Amyloid Formation}

\section{$\beta$-Amyloid Gene Expression in RPE Cells}

Using real time PCR, we were able to observe significant increases in expression of several genes involved in the formation of $\beta$-amyloid after exposure to both concentrations of isoflurane. Exposure to 1.2\% Isoflurane resulted in increased expression of the genes APPBP2 ( $\mathrm{P}=0.046)$ and BACE1 $(\mathrm{P}=0.056)$. Exposure to $3.5 \%$ Isoflurane resulted in increased expression of APH1A $(\mathrm{P}=0.046)$, APH1B $(\mathrm{P}=0.020)$, APPBP2 $(\mathrm{P}=$ $0.001)$, and NCSTN $(P=0.002)$ (Figure 3a).

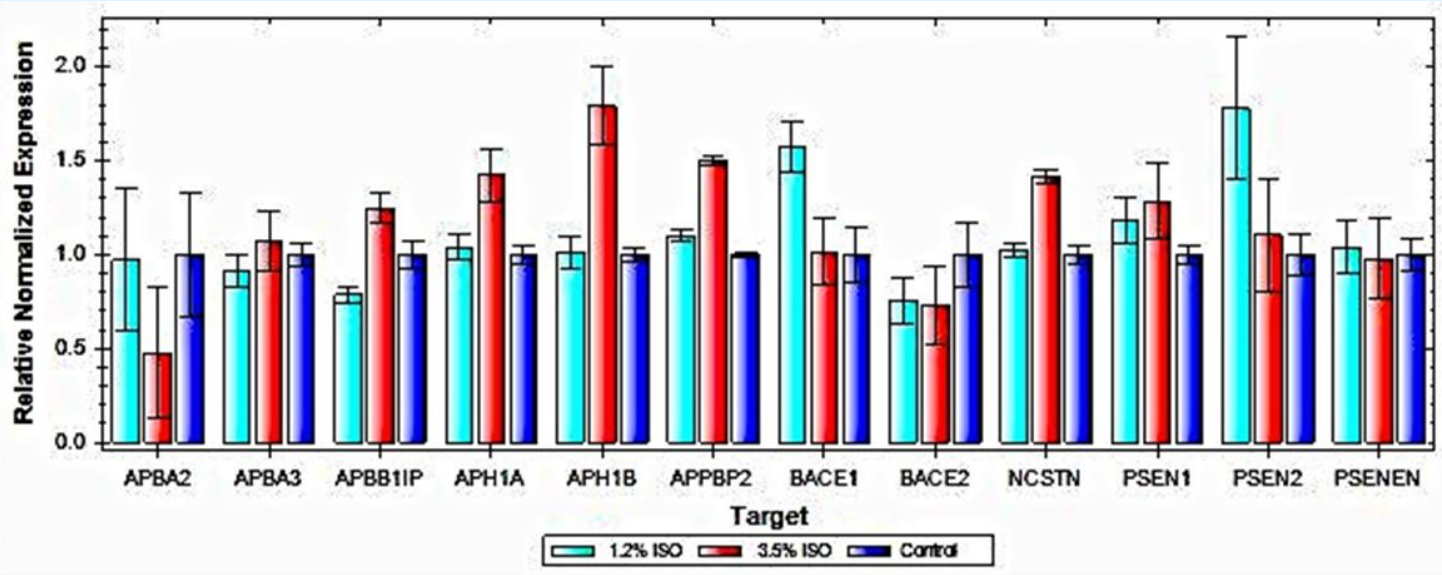

Figure 3A: $\beta$-Amyloid Gene Expression in RPE cells.

Real time PCR results demonstrating relative normalized expression of several genes linked to the formation of $\beta$-amyloid. Expression was normalized to expression of the housekeeping gene GAPDH. After exposure to isoflurane, increases were significantly observed in expression of Amyloid Beta Precursor Protein Binding Protein 2(APPBP2), Beta Secretase1(BACE1),Aph-1 Homolog A, Gamma-Secretase Subunit (APH1A),Aph-1 Homolog B, Gamma-Secretase
Subunit(APH1B) and Nicastrin(NCSTN). The effect seems to be more at $3.5 \%$ Isoflurane except for APBA2 and BACE1 PSEN2.

\section{Apoptotic Gene Expression in RPE Cells}

Using real time PCR, we were able to reveal a significant increase in expression of the pro-apoptotic gene JUN afterexposure for 4 hours to $1.2 \%$ isoflurane $(\mathrm{P}$ $=0.045)$ and $3.5 \%$ isoflurane $(\mathrm{P}=0.017)$ (Figure $3 \mathrm{~b})$.

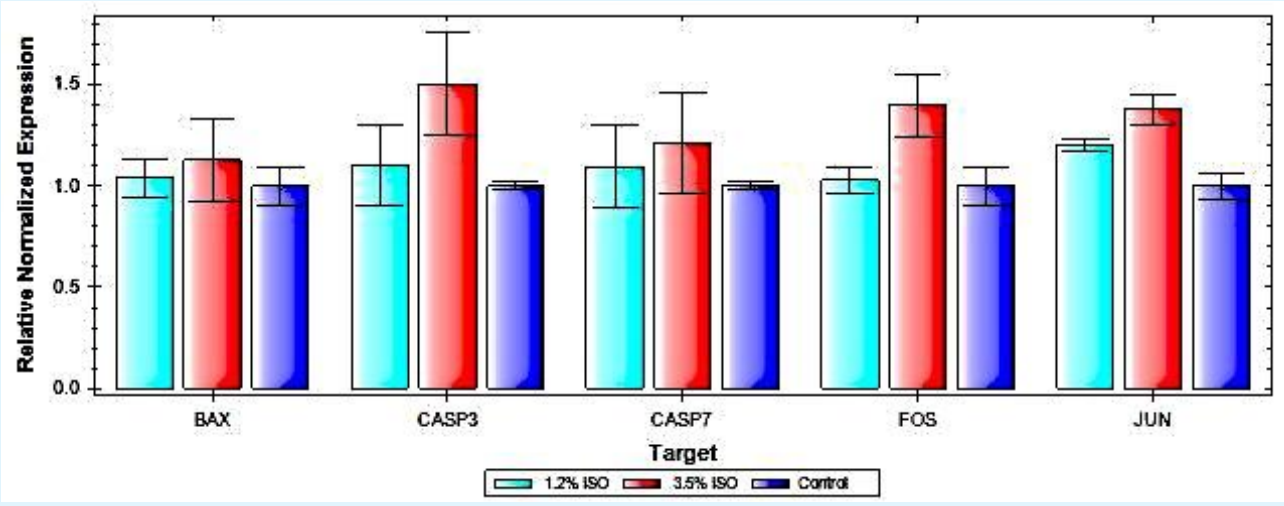

Figure 3B: Apoptotic Gene Expression in RPE cells. Real time PCR results demonstrating relative normalized expression of several genes linked to apoptosis. Expression was normalized to expression of the housekeeping gene GAPDH. After exposure to isoflurane, significant increases were observed in expression of the pro-apoptotic transcription factor JUN. 


\section{Open Access Journal of Ophthalmology}

\section{Cell Cycle Regulation Gene Expression in RPE cells}

Using real time PCR, we were observed significant increases in expression of several genes linked to cell cycle regulation after exposure to both concentrations of isoflurane. Exposure to $1.2 \%$ Isoflurane led to a significant increase in the expression of POLD1 $(\mathrm{P}=$ 0.020).Exposure to $3.5 \%$ Isoflurane led to significant increases in expression of several genes, including CCNA2 $(\mathrm{P}=0.037), \operatorname{MCM} 2(\mathrm{P}=0.049)$ and RBL2 $(\mathrm{P}=0.045)$ (Figure 3c).

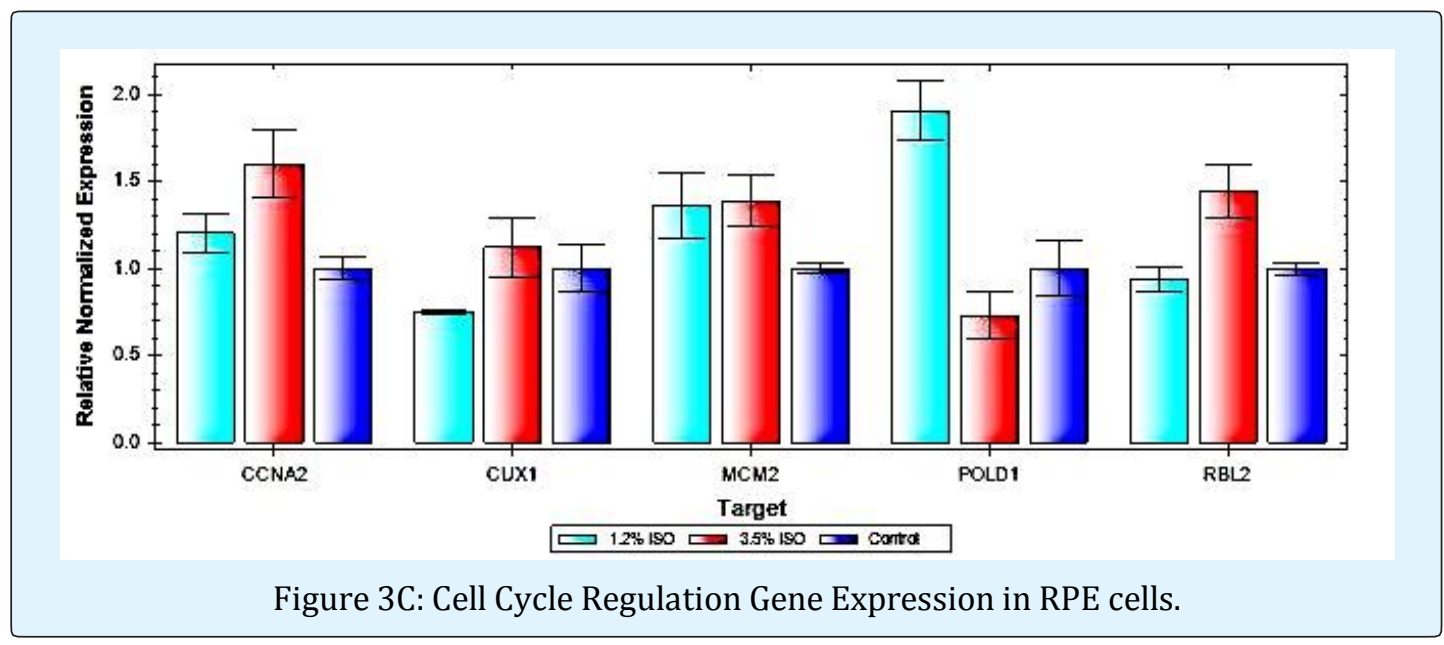

Real time PCR results demonstrating relative normalized expression of several genes associated with cell cycle progression. Expression was normalized to expression of the housekeeping gene GAPDH. After exposure to isoflurane, increases were observed in expression of DNA Polymerase Delta 1, Catalytic Subunit (POLD1), Cyclin A2 (CCNA2), Minichromosome Maintenance Complex Component 2 (MCM2) and RB Transcriptional Co repressor like 2 (RBL2).

\section{Discussion}

This study evaluates the impact of volatile anesthetics on the retina and their ability to trigger apoptosis and neurodegenerative diseases. Apoptosis is an essential process that controls, among other things, cell number during development and the removal of cells that have undergone irreparable damage [27]. The physical and biochemical events that control cellular suicide are remarkably well conserved. A group of at least 13 cysteine proteases, collectively known as caspases, function as effectors of apoptotic signaling pathways [28]. Apoptosis involves the proteolysis of specific cellular proteins by a group of cysteine proteases known as caspases. Many of these cellular targets are either functionally inactivated (e.g. poly(ADP-ribose) polymerase) or activated (e.g. other caspases, gelsolin) by such processing, thereby facilitating the cell death process. In addition, Cleavage of DFF-45 (DNA fragmentation factor subunit alpha) /ICAD (Inhibitor of caspase-activated DNase) by multiple caspases including caspase- 3 and caspase-7 is essential for its function during apoptosis [29].

Experiments demonstrated an increase in caspase 3/7 activity which was also supported by increase in their genes expression using RT.PCR, suggesting that isoflurane induced similar pro-apoptotic changes within the cells of the retina. The observed increase in caspase 3/7 levels also varied proportionally with the concentration of isoflurane that samples were exposed to, suggesting that higher doses of anesthesia may have higher potential to cause retinal damage. Here we demonstrated that exposure RPE cells to volatile anesthetics promote an increase in caspase- 3 and caspase-7 which are the principal mediators of apoptosis

Another aspect of neurodegenerative diseases is role of free radicals on neuronal biochemical composition, mainly the impact of ROS/RNS on unsaturated lipids which are labile to oxidative modification [30]. The brain is considered abnormally sensitive to oxidative damage due to higher level of fatty acids and lower in antioxidant $[31,32]$. In addition to that, human brain has higher level of iron in certain regions and in general has high levels of ascorbate. Studies concluded that neural cells are considered to be more susceptible to oxidative damage as compared to other body tissues [33]. Inhaled anesthetics have been shown to increase inflammatory biomarkers such as ROS/RNS within neuronal tissues and their 


\section{Open Access Journal of Ophthalmology}

possible role in postoperative cognitive dysfunction (POCD) [4,5]. We demonstrated a similar increase in ROS/RNS levels within the lysate of RPE cells, suggesting that inhaled anesthetics have similar toxic effects on RPE cells and it will be important to look closer to the associating of volatile anesthetics to retinal neurodegenerative diseases such as AMD.

At the level of transcription, we found a significant increase in the expression of JUN but a non-significant increase in Fos and Bax, a transcription factor that has been implicated in the development of neurodegenerative disorders, after exposure for 4 hours of exposure to $1.2 \%$ Isoflurane and $3.5 \%$ Isoflurane and two hours of incubation [34]. These changes provide impetus to the possibility that isoflurane may have pro-apoptotic effects on retinal cell populations. RT-PCR was conducted only after two hours past the exposure. This short time window was enough to trigger significant increase in JUN gene expression which the first step in apoptotic changes but perhaps this short time window was not enough to trigger the others especially Fos and Bax which are known to be activated in response to JUN activation.

Strong Jun induction in neurons destined to die by an apoptotic process suggests that this transcription factor may have a role in the programmed cell death signal transduction pathway. Jun expression has been shown to precede DNA fragmentation and cell death produced by cytotoxic drugs, DNA damaging agents, ionizing radiation, and focal ischemia [35-38]. In contrast, fos protein induction is both weaker and slower response compared to JUN in neurons undergoing PCD both during development $[39,40]$ and after a number experimental brain injuries [41-45].

Previous reports have noted the cell cycle reentry by quiescent neural tissue in the context of degenerative disease and neural injury [46], After exposing RPE cells to $3.5 \%$ isoflurane we observed significant increases in CCNA2 (Cyclin A2) expression was significantly increased. CCNA2 serves a key role in the process of cell cycle entry and progression. MCM2 (Minichromosome Maintenance Complex Component 2) expression was significantly increased after exposure to $3.5 \%$ isoflurane. The MCM2 gene product is involved in the initiation of eukaryotic genome replication fork, and thus plays a key role in cell progression [47]. POLD1 (DNA Polymerase Delta 1, Catalytic Subunit) expression was significantly increased after exposure to $1.2 \%$ isoflurane. POLD1 encodes for a component of the DNA polymerase complex, which allows for DNA replication [48]. RBL2 (RB Transcriptional Corepressor Like 2) expression was significantly increased after exposure to $3.5 \%$ isoflurane. The RBL2 gene product plays a role similar to the retinoblastoma gene in regulating entry into the cell cycle [49]. Together, these findings suggest that isoflurane imparts some degree of stress on retinal cells, and pushes these formerly quiescent cells in the direction of cell cycle entry.

The most significant finding in this experiment occurs regarding $\beta$-amyloid formation which is the link between AMD and AD. Using RT-PCT, Isoflurane treated RPE cells expressed higher levels of many genes expression that are involved in the formation of $\beta$-amyloid protein. Amyloid precursor protein (APP) can be processed in different ways by different sets of enzymes - one major pathway leads to amyloid plaque formation (amyloidogenic), while another does not (non-amyloidogenic). Usually about $90 \%$ of APP enters the non-amyloidogenic pathway, and $10 \%$ the amyloidogenic one, but these ratios can change due to mutations, environmental factors, as well as the age of the individual. Cleavage products from both these pathways may play important roles in neural development and function. An up regulation of beta and gamma secretases, would mediate a shift from non amyloidogenic to amyloidogenic pathway and leads to formation of insoluble $\beta$-amyloid, and could contribute to the pathogenesis of AMD.

Alzheimer's disease (AD) is characterized by an accumulation of amyloid beta peptides (Abeta). The production of Abeta requires two sequential cleavages induced by beta- and gamma-secretases on the betaamyloid precursor protein (APP). Altered activity of betaand gamma secretases is involved in the pathogenesis of AD. APPBP2 (Amyloid Beta Precursor Protein Binding Protein 2) expression was increased after exposure to $1.2 \%$ and $3.5 \%$ Isoflurane. APPBP2 encodes for a protein involved in Amyloid Precursor Protein (APP) transport and processing, and is thus key to replenishing cell surface APP in pro-amyloidogenic conditions [50]. On the other side, we demonstrated altered activity in beta- and gamma secretases genetic expression. In regard to Beta secretase, we also observed an increase in BACE1 (Beta Secretase-1) expression after exposure to $1.2 \%$ Isoflurane. BACE1 encodes for a trans membrane protease that plays a key role in the formation of $\beta$ amyloid plaque via cleavage of APP [51]. Lastly, NCSTN (Nicastrin) expression was significantly increased after exposure to $3.5 \%$ Isoflurane. NCSTN encodes for a subunit of the aforementioned $\gamma$-secretase complex involved in the cleavage of APP and the formation of $\beta$-amyloid plaque. Regarding Gamma secretase, APH1A (Aph-1 Homolog A, Gamma-Secretase Subunit) and APH1B (Aph1 Homolog B, Gamma-Secretase Subunit) expression were 


\section{Open Access Journal of Ophthalmology}

significantly increased after exposure to $3.5 \%$ Isoflurane. Both genes are a component of the $\gamma$-secretase complex that is involved in the final cleavage of Amyloid Precursor Protein (APP) into insoluble form of amyloid andit has been implicated in the development of Alzheimer's disease progression [52].

The current study has several limitations. It is unknown whether the observed changes in the present study could be reproduced in vivo, and the degree to which testing conditions replicate the natural milieu of the retina in the setting of general anesthesia is still largely unknown. In the future, we plan to test different concentrations and types of anesthetics with varied exposure durations. We are also seek to study the underlying mechanism responsible for these genetic up regulation, and other confounding factors such as age, sex and ethnic background. Nevertheless, our results of the present study support the evidences suggesting that anesthetics may have neurotoxic effects on the brain and especially retinal cells.

\section{References}

1. Keenan TD, Goldacre R, Goldacre MJ (2014) Associations between age-related macular degeneration, Alzheimer disease, and dementia: record linkage study of hospital admissions. JAMA Ophthalmology 132(1): 63-68.

2. Sivak JM (2013) The aging eye: common degenerative mechanisms between the Alzheimer's brain and retinal disease. Invest Ophthalmol Vis Sci 54(1): 871880.

3. Ohno-Matsui K (2011) Parallel findings in age-related macular degeneration and Alzheimer's disease. Prog Retina Eye Res 30(4): 217-238.

4. Ancelin ML, de Roquefeuil G, Scali J, Bonnel F, Adam JF, et al. (2010) Long-term post-operative cognitive decline in the elderly: the effects of anesthesia type, apolipoprotein E genotype, and clinical antecedents. J Alzheimer Dis 22(3): 105-113.

5. Goldstein MZ, Fogel BS, Young BL (1996) Effect of elective surgery under general anesthesia on mental status variables in elderly women and men: 10 -month follow-up. Int Psychogeriatric 8(1): 135-149.

6. Brown RC, Lockwood AH, Sonawane BR (2005) Neurodegenerative diseases: an overview of environmental risk factors. Environ Health Perspect 113(9): 1250-1256.
7. Xie Z, Dong Y, Maeda U, Alfille P, Culley DJ, et al. (2006) The common inhalation anesthetic isoflurane induces apoptosis and increases amyloid beta protein levels. Anesthesiology 104(5): 988-994.

8. Hussain M, Berger M, Eckenhoff RG, Seitz DP (2014) General anesthetic and the risk of dementia in elderly patients: current insights. Clinical Interv Aging 9: 1619-1628.

9. Perucho J, Rubio I, Casarejos MJ, Gomez A, RodriguezNavarro JA, et al. (2010) Anesthesia with isoflurane increases amyloid pathology in mice models of Alzheimer's disease. J Alzheimer Dis 19(4): 12451257.

10. Eckenhoff RG, Johansson JS, Wei H, Carnini A, Kang B, et al. (2004) Inhaled anesthetic enhancement of amyloid-beta oligomerization and cytotoxicity. Anesthesiology 101(3): 703-709.

11. Wu X, Lu Y, Dong Y, Zhang G, Zhang Y, et al. (2012) The inhalation anesthetic isoflurane increases levels of proinflammatory TNF-[alpha], IL-6, and IL-1[beta]. Neurobiology Aging 33(7): 1364-1378.

12. Callaway JK, Jones NC, Royse CF (2012) Isoflurane induces cognitive deficits in the Morris water maze task in rats. Eur J Anesthesia 29(5): 239-245.

13. Lee BH, Chan JT, Kraeva E, Peterson K, Sall JW (2014) Isoflurane exposure in newborn rats induces longterm cognitive dysfunction in males but not females. Neuropharmacology 83: 9-17.

14. Flick RP, Katusic SK, Colligan RC, Wilder RT, Voigt RG, et al. (2011) Cognitive and behavioral outcomes after early exposure to anesthesia and surgery. Pediatrics 128(5): e1053-e1061.

15. DiMaggio C, Sun LS, Li G (2011) Early childhood exposure to anesthesia and risk of developmental and behavioral disorders in a sibling birth cohort. Anesth Analg 113(5): 1143-1151.

16. Sprung J, Flick RP, Wilder RT, Katusic SK, Pike TL, et al. (2009) Anesthesia for cesarean delivery and learning disabilities in a population-based birth cohort. Anesthesiology 111(2): 302-310.

17. Lee TA, Wolozin B, Weiss KB, Bednar MM (2005) Assessment of the emergence of Alzheimer's disease following coronary artery bypass graft surgery or percutaneous transluminal coronary angioplasty. J Alzheimer Dis 7(4): 319-324. 


\section{Open Access Journal of Ophthalmology}

18. Chen PL, Yang CW, Tseng YK, Wei ZS, Jane LW, et al. (2014) Risk of dementia after anesthesia and surgery. Br J Psychiatry 204(3): 188-193.

19. Vanderweyde T, Bednar MM, Forman SA, Wolozin B (2010) Iatrogenic risk factors for Alzheimer's disease: surgery and anesthesia. J Alzheimer Dis 22(3): 91104.

20. Rajaram S, Nash HA (2004) A specific alteration in the electroretinogram of Drosophila melanogaster is induced by halothane and other volatile generalanesthetics. Anesth Analg 98(6): 1705-1711.

21. Yagi M, Tashiro C, Yoshiya I (1989) Changes in the electroretinogram duringenflurane anesthesia. Masui 38(11): 1438-1443.

22. Tashiro C, Muranishi R, Gomyo I, Mashimo T, Tomi K, et al. (1986) Electroretinogram as a possible monitor of anesthetic depth. Graefes Arch Clinical Exp Ophthalmol 224(5): 473-476.

23. Gomyo I, Muranishi R, Tashiro C, Uchida T, Yoshiya I (1987) The effects of enflurane and isoflurane on the electroretinogram in rabbits. Masui 36(8): 12641268.

24. Chong CM, Zheng W (2016) Artemisinin protects human retinal pigment epithelial cells from hydrogen peroxide-induced oxidative damage through activation of ERK/CREB signaling. Redox Biology 9: 50-56.

25. Frade JM, Ovejero-Benito MC (2015) Neuronal cell cycle: the neuron itself and its circumstances. Cell Cycle 14(5): 712-720.

26. Schnichels S, Hagemann U, Januschowski K, Hofmann J, Bartz-Schmidt KU, et al. (2013) Comparative toxicity and proliferation testing of aflibercept, bevacizumab and ranibizumab on different ocular cells. Br J Ophthalmol 97(7): 917-923.

27. Kerr JF, Wyllie AH, Currie AR (1972) Apoptosis: a basic biological phenomenon with wide-ranging implications in tissue kinetics. Br J Cancer 26(4): 239257.

28. Cryns V, Yuan J (1998) Proteases to die for. Genes Dev 12(11): 1551-1570.

29. Tang D, Kidd VJ (1998) Cleavage of DFF-45/ICAD by multiple caspases is essential for its function during apoptosis. J Biol Chem 273(44): 28549-28552.
30. Butterfield DA, Castegna A, Lauderback CM, Drake J (2002) Evidence that amyloid $\beta$-peptide induced lipid peroxidation and its sequelae in Alzheimer's disease brain contribute to neuronal death. Neurobiology. Aging 23(5): 655-664.

31. Chance B, Sies H, Boveris A (1979) Hydroperoxide metabolism in mammalian organs. Physiol Rev 59: 527-605.

32. Zaleska MM, Floyd RA (1985) Regional lipid peroxidation in rat brain in vitro: possible role of endogenous iron. Neuro chemical Res 10: 397-410.

33. Floyd RA, Carney JM (1992) Free radical damage to protein and DNA: Mechanism involved and relevant observations on brain undergoing oxidative stress. Ann Neurol 32: S22-27.

34. Gillardon F, Bäurle J, Wickert H, Grüsser-Cornehls U, Zimmermann M (1995) Differential regulation of bcl2, bax, c-fos, junB, and krox-24 expression in the cerebellum of Purkinje cell degeneration mutant mice. J Neurosci Res 41(5): 708-715.

35. Rubin E, Kharbanda S, Gunji H, Kufe D (1991) Activation of the c-jun protooncogene in human myeloid leukemia cells treated with etoposide. Mol Pharmacol 39(6): 697-701.

36. Ferrer I, Pozas E, Marti M, Blanco R, Planas AM (1997) Methylazoxy- methanol acetate-induced apoptosis in the external granule cell layer of the developing cerebellum of the rat is associated with strong c-Jun expression and formation of high molecular weight cJun complexes. J Neuropathol Exp Neurol 56(1): 1-9.

37. Manome Y, Datta R, Fine HA (1993) Early response gene induction following DNA damage in astrocytoma cell lines. Biochem Pharmacol 45(8): 1677-1684.

38. Soriano MA, Ferrer I, Rodriguez-Farre E, Planas AM (1996) Apoptosis and c-Jun in the thalamus of the rat following cortical infarction. Neuro Report 7(2): 425428.

39. Gonzalez-Martin C, de Diego I, Fairen A, Mellstrom B, Naranjo JR (1991) Transient expression of c-fos during the development of the rat cerebral cortex. Dev Brain Res 59(1): 109-112.

40. Gonzalez-Martin C, de Diego I, Crespo D, Fairen A (1992) Transientc-fos expression accompanies naturally occurring cell death in the developing 


\section{Open Access Journal of Ophthalmology}

interhemispheric cortex of the rat. Dev Brain Research 68(1): 83-95.

41. Afshari CA, Bivins HM, Barrett JC (1994) Utilization of a Fos-lacZplasmid to investigate the activation of cfos during cellular senescence and Okadaic Acidinduced apoptosis. J Gerontol Biol Sci 49(6): B263B269.

42. Smeyne RJ, Vendrell M, Hayward M, Baker SJ, Miao GG, et al. (1993) Continuous c-fogs expression precedes programmed cell death in vivo. Nature 363(6425): 166-169.

43. Schreiber SS, Najm I, Tocco G, Baudry M (1993) Coexpression of HSP72 and c-fos in rat brain following kainic acid treatment. Neuro Report 5(3): 269-272.

44. Kasof GM, Mandelzys A, Maika SD, Hammer RE, Curran T, et al. (1995) Kainic acid-induced neuronal death is associated withDNA damage and a unique immediate-early gene response inc-fos-lacZ transgenic rats. J Neurosci 15(6): 4238-4249.

45. Popovici T, Represa A, Crepel V, Barbin G, Beudoin M, et al. (1990) Effects of kainic acid-induced seizures and ischemia onc-fos-like proteins in rat brain. Brain Res 536: 183-194.

46. Frade JM, Ovejero-Benito MC (2015) Neuronal cell cycle: the neuron itself and its circumstances. Cell Cycle 14(5): 712-720.
47. Bai G, Smolka MB, Schimenti JC (2016) Chronic DNA Replication Stress Reduces Replicative Lifespan of Cells by TRP53-Dependent, microRNA-Assisted MCM2-7 Downregulation. PLoS Genetics 12(1): e1005787.

48. Song J, Hong P, Liu C, Zhang Y, Wang J, et al. (2015) Human POLD1 modulates cell cycle progression and DNA damage repair. BMC Biochemistry 16: 14.

49. Ullah F, Khan T, Ali N, Faraz AM, Mahmood AK, et al. (2015) Promoter Methylation Status Modulate the Expression of Tumor Suppressor (RbL2/p130) Gene in Breast Cancer. PLoS ONE 10(8): e0134687.

50. Kuan YH, Gruebl T, Soba P, Eggert S, Nesic I, et al. (2006) PAT1a modulates intracellular transport and processing of amyloid precursor protein (APP), APLP1, and APLP2. J Biol Chem 281(52): 4011440123.

51. Teich AF, Arancio O (2012) Is the Amyloid Hypothesis of Alzheimer's disease therapeutically relevant? Biochemical J 446(2): 165-177.

52. De Strooper B, Saftig P, Craessaerts K, Vanderstichele H, Guhde G, et al. (1998) Deficiency of presenilin-1 inhibits the normal cleavage of amyloid precursor protein. Nature 391(6665): 387-390. 